Relations industrielles

Industrial Relations

\title{
Economic Aspects of Education, par W.C. Bowen, Industrial Relations Section, Princeton University, 1964.
}

\section{Jacques St-Laurent}

Volume 19, numéro 3, juillet 1964

URI : https://id.erudit.org/iderudit/1021289ar

DOI : https://doi.org/10.7202/1021289ar

Aller au sommaire du numéro

Éditeur(s)

Département des relations industrielles de l’Université Laval

ISSN

0034-379X (imprimé)

1703-8138 (numérique)

Découvrir la revue

Citer ce compte rendu

St-Laurent, J. (1964). Compte rendu de [Economic Aspects of Education, par W.C. Bowen, Industrial Relations Section, Princeton University, 1964.] Relations industrielles / Industrial Relations, 19(3), 410-410.

https://doi.org/10.7202/1021289ar

Tous droits réservés (C Département des relations industrielles de l’Université Laval, 1964
Ce document est protégé par la loi sur le droit d'auteur. L'utilisation des services d'Érudit (y compris la reproduction) est assujettie à sa politique d'utilisation que vous pouvez consulter en ligne.

https://apropos.erudit.org/fr/usagers/politique-dutilisation/ 
cessus de la prise de décision dans l'entreprise moderne en termes de variables qui offectent les buts, les expectatives et le choix de l'organisation. Les concepts relationnels, qui représentent ò plusieurs aspects le coeur de leur théorie de la décision, sont les suivonts: 1) «quosi resolution of conflict \$2) \&uncertainty ovoidonce 》3) «problemistic search: \$, 4) * organizational learning $\gg$.

A partir de ce cadre d'onalyse, les auteurs bâtissent un nombre de modèles et en suggèrent les implications pour la théorie économique et celle de l'organisation. Selon eux, le langoge théorique naturel dans ce contexte est celui du programme d'un ordinateur. Au chapitre 7 , on trouve un modèle de la déterminatión du prix et de la production dans un magasin à rayons. Au chapitre suivant, les auteurs exposent un modèle général de détermination du prix et de la production dans un oligopole; de plus, ils examinent quelques propriétés du modèle. Dans les chapitres 9 et 10, on peut prendre connaissance de deux modèles: le premier, du comportement administratif rationel et l'outre, du comportement d'une société de fiducie dans l'investissement.

Tout en n'étont pas très facile, ce volume ouvre des horizons nouveaux sur le comportement des administrateurs, particuiièrement dons le domaine du processus de la prise de décision, et partant présente un intérêt certain pour la plupart de ceux qui s'intéressent à l'administration de l'entreprise.

\section{Bertrand Belzile}

\section{Economic Aspects of Education, par W.C. Bowen, Industrial Relotions Section, Princeton University, 1964.}

Dons une province où les problèmes posés por un changement considérable dans la demande de services d'éducation ont causé et causent encore des perturbotions appréciables, les trois excellents essais du professeur W.C. Bowen devraient intéresser un bon nombre de personnes.

Le premier de ces essais est une évoluotion des différentes méthodes utilisées par les économistes pour mesurer le rendement économique des investissements dons le secteur de l'éducation. II devrait intéresser non seulement les économistes, mais tous ceux qui ont soit à élaborer les politiques d'éducation, soit à les accepter ou les refuser. Soulignons plus particulièrement lo section qui troite des projections de maind'oeuvre comme guide pour les planificoteurs.
Le deuxième essoi traite du financement des universités en Gronde-Bretagne et en France. L'analyse qu'on y fait est cependant d'application universelle puisqu'elle réfère à des problèmes qui sont pour nous d'un intérêt aussi actuel que l'efficacité du système universitaire, l'importance du revenu de la nation qu'on doit y offecter, le recrutement des professeurs, l'équilibre que I'on doit tenir entre les humanités et les sciences, l'enseignement et lo recherche, etc.

Dans le troisième essai, l'auteur discute des disporités de traitements dans les universités anglaises et tente d'en apprécier I'utilité et les conséquences. Ceux qui réalisent que le mécanisme des prix est un puissont facteur d'allocation des ressources humaines autant que physiques en trouveront une excellente illustration ici. Ceux qui ont la responsabilité de recruter les professeurs y trouveront d'utiles informations capables de faciliter l'élaboration de leur politique de recrutement.

\section{Jacques St-Lourent}

\section{Ethics ans Standards in American Business,} par Joseph W. Towle and others. Houghton Mifflin Co., Boston, 1964. 1964. 315 poges.

Nombreux volumes et articles ont été publiés aux Etats-Unis à la suite de l'ouvrage de H.R. Bowen sur la responsabilité sociale des administrateurs et hommes d'offaires. Qu'il suffise de mentionner ici les livres et articles de Berle et Means, Dempsey et Duff. L'intérêt porté aux problèmes de la moralité et la responsabilité sociale en affaires trouve une explication dans les changements suivants: le déclin de la concurrence pure pour foire place ò l'oligopole, la séparation entre la possession des moyens de production et leur contrôle, l'intervention des gouvernements dans l'orientation de l'économie, la tendance ò la professionalisation chez les administrateurs, les tentatives de collusion pour fixer les prix et le renouveau dans l'Eglise en matière économique et sociale.

L'ouvrage que nous recensons porte sur les problèmes moraux qui ont occasionné ces changements. C'est le compte-rendu d'un symposium tenu ò l'Université de Washington, ouquel participaient des représentants des milieux ocodémiques, administrotifs et religieux.

La présentation du motériel tente d'établir une certaine unité entre des exposés qui ne sont pas tous d'égale voleur et qui véhiculent des points de vue antithétiques. 